\title{
The Theoretical Studies of the Cultivation of Three Cotton Seeds along the Plain
}

\author{
Obidov Avazbek, Sultonov Mirzaolim, Muhksinov Ibrohim, Abdullaev Shokir \\ Namangan Institute of Engineering and Technology, Namangan, Uzbekistan \\ Email: aobidov@list.ru
}

How to cite this paper: Avazbek, O., Mirzaolim, S., Ibrohim, M. and Shokir, A. (2018) The Theoretical Studies of the Cultivation of Three Cotton Seeds along the Plain. Engineering, 10, 514-520. https://doi.org/10.4236/eng.2018.108037

Received: May 26, 2018

Accepted: August 12, 2018

Published: August 15, 2018

Copyright $\odot 2018$ by authors and Scientific Research Publishing Inc. This work is licensed under the Creative Commons Attribution International License (CC BY 4.0).

http://creativecommons.org/licenses/by/4.0/

\begin{abstract}
As it is known, the main purpose of production of cotton fiber in the technological processes is to produce high quality cotton fiber. Lots of processes in the enterprise have a loss of cotton fiber, which is a valuable raw material for the textile industry.
\end{abstract}

\section{Keywords}

Cotton, Cotton Fiber, Lower Seeds, Surface, Frequency, Thickness, Corner, Separated, Coordinate System, Vibro-Catcher

\section{Introduction}

The production of cotton products and the cotton industry occupies an important place in the economy of Uzbekistan, as a result of which a number of decrees and higher-level decisions on the cardinal transformation of this sphere of the economy have been adopted lately [1] [2], and the output of cotton for the last 5 years has been declining its consumption within the country is gradually increasing [3]. The country is striving to rebuild its economy with the production of deep processing of cotton, bringing raw cotton to finished products. Therefore, scientific research aimed at improving the quantitative and qualitative indicators of cotton products for the country is of great importance.

Currently mechanical method of catching not-well-ginned seeds and free fiber is being used, and in this process fiber and seeds can get harmed as well.

One of the main advantages of vibro-catchers for not-ginned fractions of cotton seeds and free fiber is the absence of punching effect to material. At our institute and at "Kosonsoy cotton fiber" company, a kinematic awakening device was designed and manufactured to capture unprotected seeds and free fibers.

In our research, theoretical researches on the possibility of forming 
one-layered flow of processed seed fertilizers were conducted and conditions for their acceleration were determined.

\section{Analysis of the State of Cotton Seeds Being Processed}

The most common type of freed slaughtered cotton and the state of products obtained after its destruction is the shift in the center of gravity of the particles resembling (Figure 1(a)).

We examine the static balance of three cotton seeds, which are taken in the form of short cylinders, one of which is associated with the remaining two remaining drain off surfaces. First we will consider the symmetric arrangement of the upper cylinder with the weighted velocity of $m$ and $R$ determined by $\mathrm{R}$. The lower cylinders have a homogeneous radius $\left(R_{0}\right)$ and mass $\left(m_{0}\right)$, equal to $2 I$ in the balance position.

Let's define the cylinder balance condition, in which case we call the half-corner angle as $\varphi_{0}$.

Particularly, in the cotton mass taken after ginning process, there are also fibered seeds, which can get into lint during lintering process. In order to solve this problem, devices that allow separating fibered seeds according to geometrical parameters and fertility have been tested [4] [5].

One of them is a net-faced sorting device, proposed by the authors of the article. In this article, theoretical researches on the movement and selection of seeds on the net surface of the device were conducted. Let's assume that the three seed systems move horizontally along a plain surface under a corner (Figure 2). We consider the weight of the upper and lower seeds as $m_{1}$ and $m_{2}$, considering seeds as cylinders [6]. Thus, the bottom seeds have the same weight and all three seeds have equal radiuses, and the distance between the upper and lower seeds is $l$.

From the center of the upper seeds to the plains the initial time is equal to $h_{0}$, and the unification of seeds during motion takes place only between the upper and lower seeds. At point 0 , let's set the coordinate head, we set the $O X$ axis along the plain and the $O Y$ axis at the perpendicular position. We define the coordinates of seeds as $M_{1}\left(X_{1} Y_{1}\right), M_{2}\left(X_{2} Y_{2}\right)$ and $M_{3}\left(X_{3} Y_{3}\right)$.

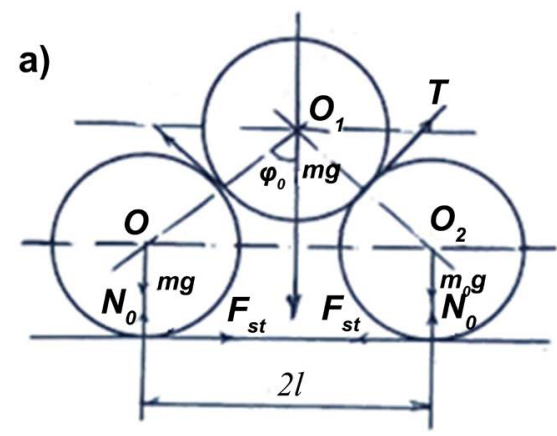

b)

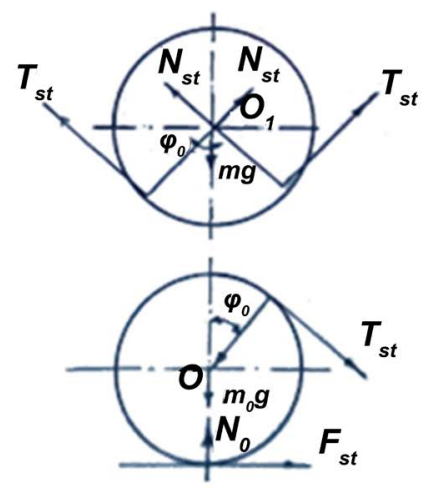

Figure 1. The location of the three seed systems. 


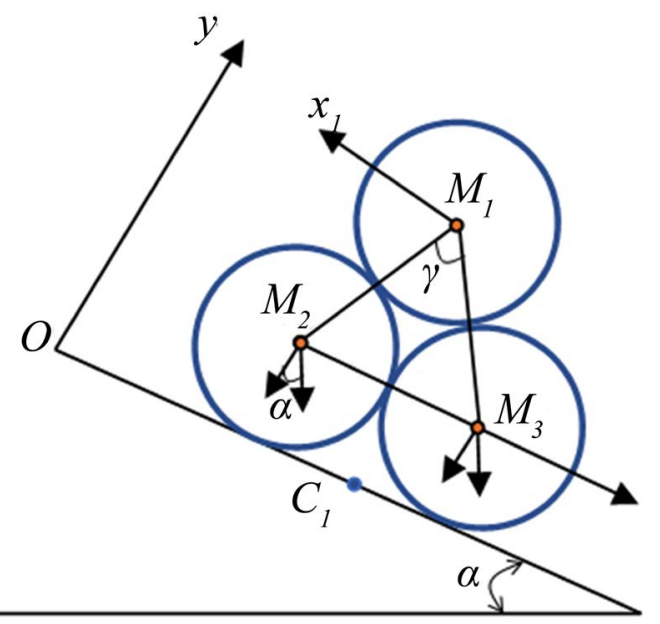

Figure 2. Scheme of three seeds on the crust.

\section{Theoretical Studies of the Movement of Seeds}

As generalized coordinates, we accept the angle $\varphi$ and $X$ between $M_{1} 0_{1}$ and $M_{1} M_{2}$ vectors. With respect to the $X 0 Y$ coordinate system, the center of cylinders is determined by following formula:

$$
\begin{array}{ll}
X_{1}=X ; & Y_{1}=h_{0}+l \cos \varphi ; \\
X_{2}=X-l \sin \varphi ; & Y_{2}=R ; \\
X_{3}=X+l \sin \varphi ; & Y_{3}=R ;
\end{array}
$$

The seeds are affected by the interaction force in areas where they are bonded together and in areas where the bottom seeds are attached to the plain [7].

The projection of the forces affecting the upper seeds will be as follows:

$$
\begin{aligned}
& X_{1}=m_{1} g \sin \lambda+f_{1} m_{1} g \cos (\varphi-\lambda) \cos \varphi-f_{1} m_{1} g \cos (\varphi+\lambda) \cos \varphi ; \\
& Y_{1}=-m_{1} g \cos \lambda+f_{1} m_{1} g \cos (\varphi-\lambda) \sin \varphi+f_{1} m_{1} g \cos (\varphi+\lambda) \sin \varphi ;
\end{aligned}
$$

Lower seeds also have the following:

$$
\begin{gathered}
X_{2}=-m_{2} g \cos (\varphi-\lambda) \sin \varphi+f_{1} m_{1} g \cos \varphi+m_{2} g f_{2} \cos \lambda ; \\
Y_{2}=m_{1} g \cos |\varphi+\lambda| \cos \varphi-f_{1} m_{1} g \cos (\varphi+\lambda) \sin \varphi-m_{2} g f_{2} \sin \lambda ; \\
X_{3}=m_{1} g \cos (\varphi-\lambda) \sin \varphi-f_{1} m_{1} g \cos (\varphi-\lambda) \sin \varphi-m_{2} g f_{2} \cos \lambda ; \\
Y_{3}=-m_{1} g \cos (\varphi-\lambda) \cos \varphi+f_{1} m_{1} g \cos (\varphi-\lambda) \sin \varphi-m_{2} g f_{2} \sin \lambda .
\end{gathered}
$$

In this: $f_{1} ; f$-coefficients of friction and the friction of cotton seeds. $Q_{x} ; Q_{y}$-to identify the aggregate forces $\delta_{x_{1}} ; \delta_{x_{2}} ; \delta_{x_{3}} ; \delta_{y_{1}} ; \delta_{y_{2}} ; \delta_{y_{3}}$. Variations:

$$
\delta_{A}=x_{1} \delta_{x_{1}}+x_{2} \delta_{x_{2}}+x_{3} \delta_{x_{3}}+y_{1} \delta_{y_{1}}+y_{2} \delta_{y_{2}}+y_{3} \delta_{y_{3}} ;
$$

Hereby, we (1) shall have the following:

$$
\begin{gathered}
\delta_{x_{1}}=\delta_{x} ; \quad \delta_{x_{3}}=\delta_{x}-l_{1} \cos \varphi \delta \varphi ; \quad \delta_{x_{3}}=\delta_{x}+l_{1} \cos \varphi \delta \varphi ; \\
\delta_{y_{1}}=-l \sin \varphi \delta \varphi ; \quad \delta_{y_{2}}=0 ; \quad \delta_{y_{3}}=0 .
\end{gathered}
$$

$\delta_{A}$ the expression for the following appears: 


$$
\begin{aligned}
\delta_{A} & =x_{1} \delta_{x_{1}}+x_{2}\left(\delta_{x}-l \cos \varphi \delta \varphi\right)+x_{3}\left(\delta_{x}+l \cos \varphi \delta \varphi\right)+y_{1}(-l \sin \varphi \delta \varphi) \\
& =\left(x_{1}+x_{2}+x_{3}\right) \delta_{x}+\left(-x_{2} l \cos \varphi-y_{1} l \sin \varphi+x_{3} l \cos \varphi\right) \delta \varphi .
\end{aligned}
$$

$Q_{x} ; Q_{y}$-we define generalized forces and their $\delta_{x}$ and $\delta_{y}$ coefficients:

$$
\begin{gathered}
Q_{x}=x_{1}+x_{2}+x_{3} ; \\
Q_{y}=l\left(-x_{2} \cos \varphi-y_{1} \sin \varphi+x_{3} \cos \varphi\right)
\end{gathered}
$$

(2), (3) and (4) $x_{1}, x_{2}, x_{3}, y_{1}$ after setting values we get the following:

$$
\begin{gathered}
Q_{x}=m_{1} g \sin \lambda+m_{1} g \sin \lambda[\cos (\varphi-\lambda)-\cos (\varphi+\lambda)] \\
=m_{1} g \sin \lambda+m_{1} g \sin ^{2} \varphi \sin \lambda \\
Q_{y}=l\left\{\left[m_{1} g \cos (\varphi+\lambda) \sin \varphi-f_{1} m_{1} g \cos (\varphi+\lambda) \cos \varphi-m_{2} g f_{2} \cos \lambda\right] \cos \varphi\right.
\end{gathered}
$$

To create an equation of motion we find the kinetic energy of the system: $T=T_{1}+T_{2}+T_{3}$; where $T_{1}, T_{2}, T_{3}$ - kinetic energy of the first, second and third seeds respectively [8] [9].

$$
\begin{aligned}
& T_{1}=\frac{m_{1}}{2}\left(\dot{x}^{2}+l^{2} \dot{\varphi}^{2} \sin ^{2} \varphi\right) ; \quad T_{2}=\frac{m_{2}}{2}(\dot{x}-l \dot{\varphi} \cos \varphi)^{2} \\
& T_{3}=\frac{m_{3}}{2}(\dot{x}+l \dot{\varphi} \sin \varphi)^{2}
\end{aligned}
$$

Total kinetic energy equals:

$$
\begin{aligned}
T & =\frac{m}{2}\left(\dot{x}^{2}+l^{2} \varphi^{2} \sin ^{2} \varphi\right)+\frac{m^{2}}{2}\left[(\dot{x}-l \dot{\varphi} \cos \varphi)^{2}+(\dot{x}+l \dot{\varphi} \sin \varphi)\right] \\
& =\frac{m}{2}\left(\dot{x}^{2}+l^{2} \varphi^{2} \sin ^{2} \varphi\right)+\frac{m^{2}}{2}\left(2 x^{2}+2 l^{2} \varphi^{2} \cos ^{2} \varphi\right) \\
& =\frac{m_{1}}{2}\left(\dot{x}^{2}+l^{2} \varphi \sin \varphi\right)+m_{2}\left(\dot{x}^{2}+l^{2} \varphi^{2} \cos ^{2} \varphi\right)
\end{aligned}
$$

This equation is integrated with Runge-Kutta method on the following initial conditions:

$$
\text { when } t=0 \text { then } \varphi=\varphi_{0}, \dot{Y}=0
$$

in this: $\varphi_{0}<\varphi_{n p}, \varphi_{n p}$-the boundary angle to start the movement. It is determined by the equation: $A\left(\varphi_{0}\right)=0 ; B(\varphi)=0$.

Figure 3 shows diagrams of the separation of seed fractions under various process parameters, which show that all the graphs are descending, which corresponds to reality. At the same time, the intensity of separation is more noticeable with a low coefficient of friction, and with increasing coefficient of friction the intensity decreases substantially. However, the friction coefficient is an objective factor and it is not possible to control it during seed sorting. It should be taken as it is in fact and controlled by changing other parameters, for example, the slope angle, amplitude and frequency of the oscillating screen surface.

To solve the Equation (6) by the Runge-Kutta method, an exposure program has been created. The following conditions have been met for as account [10]:

$$
\begin{gathered}
\lambda=10^{\circ} ; \\
d=10 \mathrm{~mm} ;
\end{gathered}
$$




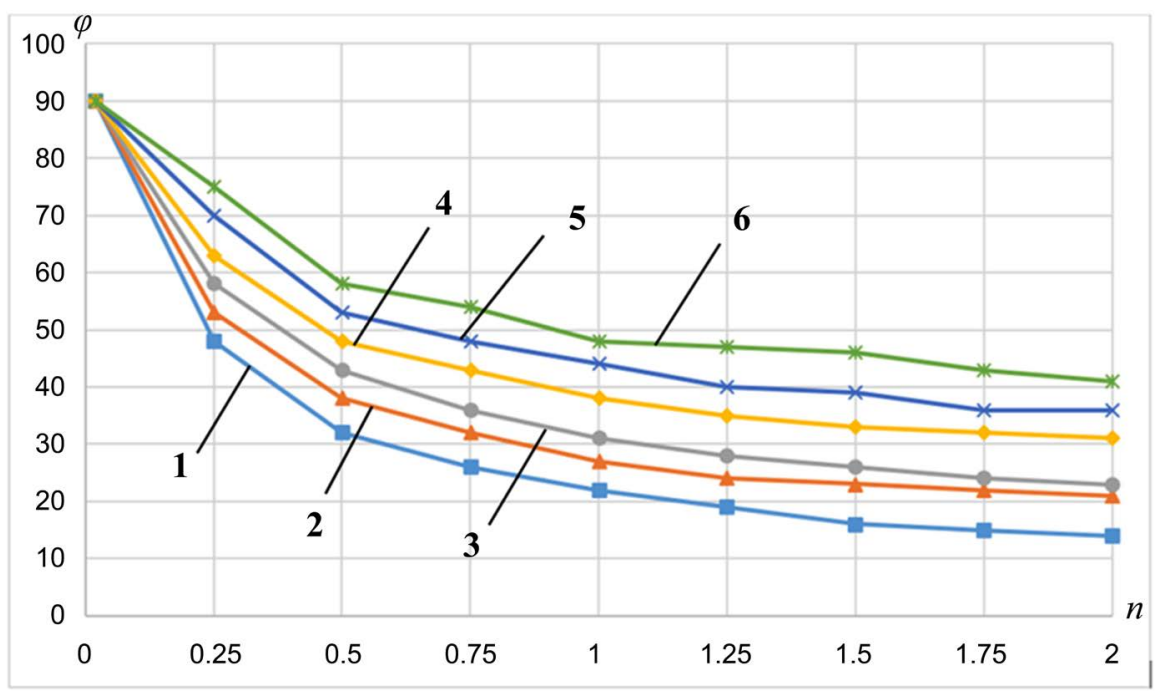

(a)

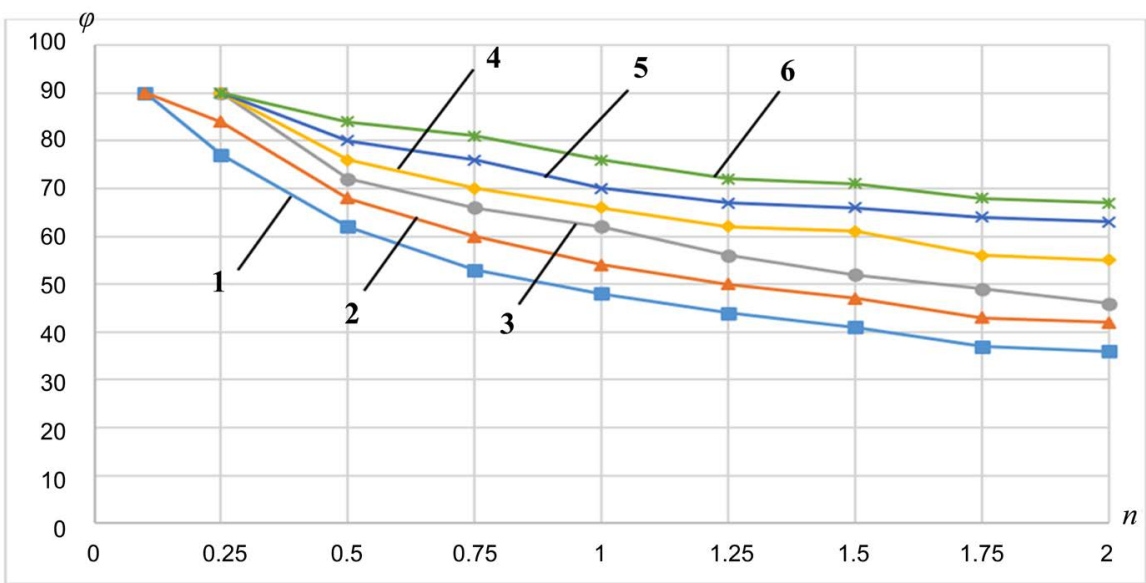

(b)

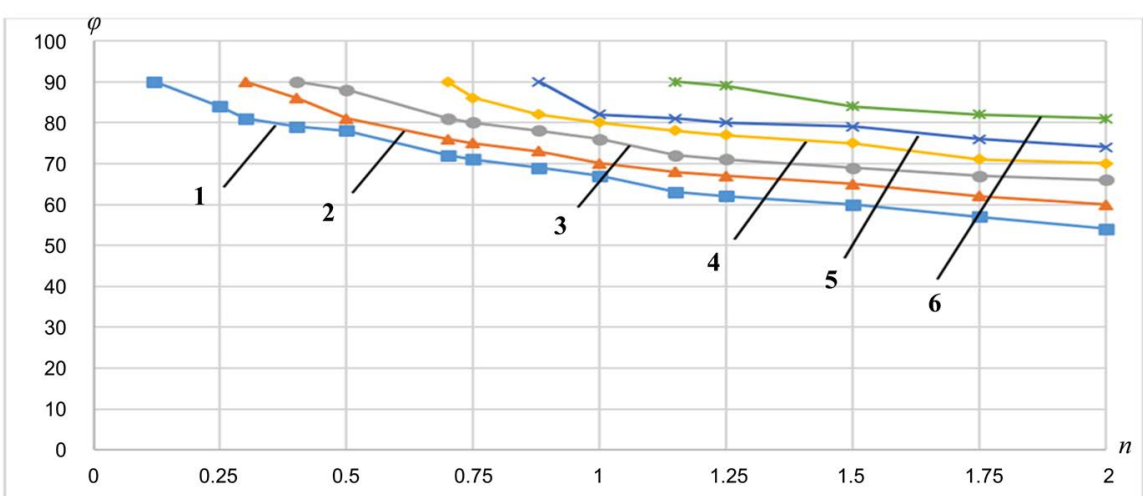

(c)

Figure 3. Three seeds recession diagrams: (a) $f_{0}=0,1$; (b) $f_{0}=0,3$; (c) $f_{0}=0,6$; 1 $f=0,1 ; 2-f=0,2 ; 3-f=0,3 ; 4-f=0,4 ; 5-f=0,5 ; 6-f=0,6$.

$$
n=1 ; \quad f_{1}=0.5 ; \quad f_{2}=0.5 ; \quad \varphi=59^{0} .
$$

Figure 4 presents the results of solving Equation 6, which show that the 

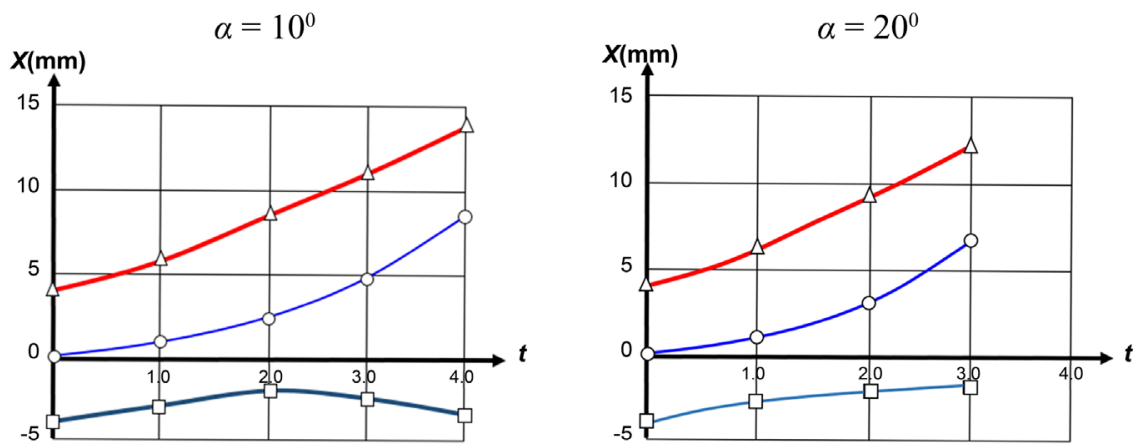

Figure 4. A timetable of movement of seeds to the surface over time $\alpha=10^{\circ}, \alpha=20^{\circ}$.

coordinates of the location of the seeds on the screening surface in time are basically of an ascending nature. And this shows that with these parameters, the seeds on the surface of the grid are moved and the sorting process is possible.

2 -there are graphs of seeds in non-linear values, obtained from the calculation of the seed residence time on a perforated surface. The theoretical calculations allowed the following conclusions. The time of movement of the top cotton in the lower plain depends on the angle of the surface, the friction coefficient for the seeds on the surface, the friction coefficient of the seeds and the initial state of the seeds.

\section{Conclusions}

Comparison of the results of the calculations with the vibration shows that the vibration of the plain helps to move the seeds together, resulting the $\begin{array}{llll}1.5 & \ldots & 2.0\end{array}$ times decrease in upper cylinders reaching the plain.

Thus, our studies recorded the main parameters that determine the process of vibrational sorting, which showed that the most effective sorting occurs at an amplitude of $A=17 \mathrm{~mm}$, frequency of $f=4 c^{-1}$, and the thickness of the seed layer does not exceed $h=30 \mathrm{~mm}$.

\section{Conflicts of Interest}

The authors declare no conflicts of interest regarding the publication of this paper.

\section{References}

[1] Prezident.uz (2017) About Measures on Cardinal Perfection of a Control System of a Cotton Industry. Decree of the President of the Republic of Uzbekistan of 28 November 2017 No. PP-3408. Press Service of the President of the Republic of Uzbekistan. Prezident.uz.

[2] Prezident.uz (2017) On Measures for the Accelerated Development of the Textile and Apparel-Knitting Industry. Decree of the President of the Republic of Uzbekistan of December 14, 2017 No.UP-5285. Press Service of the President of the Republic of Uzbekistan. Prezident.uz.

[3] ICAC (2017) Cotton This Mont. Major Changes in Supply and Demand Estimates and Projections. https://icac.generation10.net/ 
[4] Alimova, X., Burnashev, R.Z., Sarimsakov, O.Sh., Rakhimov, O. and Bulanov, A. (1999) Textile, Light and Polygraphic Promulgence in Market Conditions. Journal of Economic Herald of Uzbekistan, No. 1/2, 58.

[5] Akhmedkhodjaev, Kh.T. (2005) Fundamentals of the Theory and Technology of Derivative Ginning. Fan, Tashkent, 173.

[6] Obidov, A.A. (2007) Improvement of Technology of Cleaning and Sorting Processed Cotton Seeds. Ph.D. Dissertation, TTESI, Tashkent.

[7] Azizov, S.M. and Axmedhodjaev, K.T. (2016) The Optimal Modeling of an Angular Position of Saw Cylinders in Single-Chamber Two Cylinders Gin. American Journal of Mechanical and Industrial Engineering, 1, 103-106.

[8] Abbazov, I., Sarimsakov, O., Khodjiev, M. and Mardonov, B. (2018) Effective Cleaning of Cotton Waste Produced at Cotton Cleaning Factories. American Joural ASCIT Communications, 5, 22-28.

[9] Burnashev, R.Z., Muradov, R. and Sarimsakov, O.Sh. (2001) Dynamic Task of Interaction of Raw Cotton with Working Bodies of Processing Machines. Journal of Problems of Mechanics, No. 34, 55.

[10] Abdukarimovich, M.O., Ibragimovich, A.K. and Sharipjanovich, S.O. (2018) Designing a New Design of a Loading Cylinder for Pneumomechanical Spinning Machines. Engineering, 10, 345-356. 